\title{
REVIEW
}

\section{Fighting liver fat}

\author{
David Koeckerling ${ }^{1}$, Jeremy W Tomlinson ${ }^{2}$ and Jeremy F Cobbold ${ }^{3}$
}

${ }^{1}$ Medical Sciences Division, University of Oxford, Oxford, UK

${ }^{2}$ Oxford Centre for Diabetes, Endocrinology \& Metabolism, University of Oxford, Oxford, UK

${ }^{3}$ Oxford Liver Unit, NIHR Oxford Biomedical Research Centre, Oxford University Hospitals NHS Foundation Trust, John Radcliffe Hospital, Oxford, UK

Correspondence should be addressed to J Cobbold: Jeremy.Cobbold@ouh.nhs.uk

\begin{abstract}
Non-alcoholic fatty liver disease is a chronic liver disease which is closely associated with components of the metabolic syndrome. Its high clinical burden results from the growing prevalence, inherent cardiometabolic risk and potential of progressing to cirrhosis.

Key Words

- non-alcoholic fatty liver disease

Patients with non-alcoholic fatty liver disease show variable rates of disease progression through a histological spectrum ranging from steatosis to steatohepatitis with or without fibrosis. The presence and severity of fibrosis are the most important prognostic factors in non-alcoholic fatty liver disease. This necessitates risk stratification of patients by fibrosis stage using combinations of non-invasive methods, such as composite scoring systems and/or transient elastography. A multidisciplinary approach to treatment is advised, centred on amelioration of cardiometabolic risk through lifestyle and pharmacological interventions. Despite the current lack of licensed, liver-targeted pharmacotherapy, several promising agents are undergoing late-phase clinical trials to complement standard management in patients with advanced disease. This review summarises the current concepts in diagnosis and disease progression of non-alcoholic liver disease, focusing on pragmatic approaches to risk assessment and management in both primary and secondary care settings.

\section{Why fight liver fat?}

\section{What is NAFLD?}

Non-alcoholic fatty liver disease (NAFLD) is recognised as the most common aetiology of chronic liver disease, with an estimated global prevalence of $25.2 \%$, and as a major cause of cirrhosis and hepatocellular carcinoma (HCC), projected to become the leading indication for liver transplantation during this decade (1). NAFLD is defined as the accumulation of liver fat (exceeding $5 \%$ of hepatocytes) without evidence for coexisting hepatic insults, namely viral or autoimmune hepatitis, use of steatogenic medication, or significant alcohol intake (2). Regarded as the hepatic manifestation of the metabolic syndrome in view of its intimate association with insulin resistance, obesity, hypertension and dyslipidaemia, NAFLD is a multi-system disease encompassing a histopathological spectrum of severity. This heterogeneous continuum ranges from simple, isolated steatosis (non-alcoholic fatty liver (NAFL)) to steatohepatitis with evidence of hepatocyte injury and necroinflammation (non-alcoholic steatohepatitis (NASH)) with or without hepatic fibrosis. In its advanced stages, NAFLD may progress to cirrhosis and its complications, including HCC. Its mounting prevalence and potentially aggressive nature combined with diagnostic and therapeutic barriers make NAFLD an important public health concern of the 21st century (3). Mirroring the obesity pandemic, its clinical and economic burden is reaching enormous proportions: 52 million people are estimated to suffer from NAFLD in Germany, France, Italy and the UK, incurring annual direct medical costs of $€ 35$ billion $(2,3)$.

The heterogeneity of disease progression is reflected in the multi-faceted pathogenesis of NAFLD. Hepatocellular fat accumulation arises when lipid export or degradation

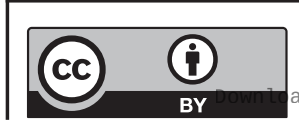

This work is licensed under a Creative Commons Attribution 4.0 International License. 
is exceeded by lipid import or synthesis. Main sources of hepatic lipid aggregation are a flux of free fatty acids (FFA) from peripheral adipose tissue (59\%), followed by hepatic de novo lipogenesis (26\%) and dietary intake (14\%) (4). Traditionally, steatosis severity is graded according to the extent of triglyceride accumulation despite the recognition that, in general, triglycerides per se do not cause hepatocyte injury. In contrast, triglyceride accumulation appears to be an adaptive mechanism minimising hepatocyte injury from lipotoxicity caused by reactive lipids and fatty acids, such as cholesterol, FFAs, oxysterols or phospholipids. In chronic nutrient surplus, the ability or inability of the liver to compensate for fatty acid exposure by synthesising triglycerides determines whether lipotoxicity ensues. If compensatory mechanisms are overwhelmed, lipotoxicity originates from the generation of reactive oxygen species and dysfunction of unfolded protein responses. Hepatocytes exposed to chronic lipotoxicity initiate dysregulated regenerative processes which perpetuate inflammatory and fibrogenic stimuli $(4,5,6$, $7,8)$. In normal homeostasis, insulin potently inhibits adipose tissue lipolysis. Insulin resistance, a fundamental characteristic of NAFLD, manipulates hepatic lipid metabolism and exacerbates adipocyte dysfunction, encouraging intrahepatic lipogenesis and fatty acid influx (7). Gut-liver axis dysfunction has been implicated in NAFLD pathogenesis through mechanisms which include generation of short-chain fatty acids, alterations in intestinal permeability and bacterial translocation into the portal vasculature $(5,6,7)$. Reductions in microbiome quality, quantity and diversity are documented in NAFLD, yet causality between 'dysbiosis' resolution and NAFLD improvement is not established (5).

\section{Natural history of NAFLD}

The complex phenotype and variable progression rate of NAFLD reflect the overlapping influences of genetics, diet, comorbidities and metabolic discrepancies between individuals. A minority of patients advances to significant fibrosis, yet ambiguity exists regarding longterm outcomes and histological progression of NAFLD (9). Epidemiologically, global NAFLD prevalence was estimated at $25.24 \%$, with highest and lowest prevalence rates in the Middle East (32\%) and Africa (14\%), respectively. Comparable estimates were reported from Europe (23.7\%) and the US (24.1\%) (1). NAFLD prevalence increases analogously with burgeoning obesity, T2DM, hyperlipidaemia and hypertension rates, doubling from $5.5 \%$ in 1980 to $11 \%$ in 2008 in the US $(1,10)$.
Over the last decade, the frequency of NAFLD as an indication for liver transplantation surged by $170 \%$ and HCC cases attributable to NAFLD simultaneously increased from $8.2 \%$ to $13.5 \%$ with NAFLD on trajectory to becoming the most common indication for liver transplantation during this decade (11).

While mortality data in NAFLD is difficult to interpret owing to discrepancies in the design of studies assessing survival, robust evidence indicates that fibrosis stage is the most relevant prognostic marker in NAFLD. Early mortality data was summarised by a meta-analysis demonstrating higher all-cause mortality for NAFLD patients compared to the general population (OR 1.57, 95\% CI: 1.18-2.10, $P=0.002$ ) (12). The predominant causes of death identified were cardiovascular complications, malignancy and liverrelated complications in descending order (13). One of the longest follow-up studies available (mean follow-up 26.4 years) supports the notion that NAFLD confers increased all-cause mortality (HR 1.29) with advanced fibrosis being the only histological parameter to predict mortality (14). Hepatic fibrosis in NAFLD is categorised relative to location and extent: stage 1 (F1) is defined as perisinusoidal fibrosis alone, stage 2 (F2) as perisinusoidal plus periportal fibrosis, stage 3 (F3) includes bridging fibrosis, and stage 4 (F4) is cirrhosis $(15,16)$. Angulo et al. analysed 619 patients with biopsy-proven NAFLD retrospectively, validating fibrosis stage as the most reliable histological characteristic to predict adverse outcomes (17). A recent meta-analysis with 17,000 patient-years follow-up substantiated these findings. All-cause mortality progressively heightened with each subsequent fibrosis stage (mortality rate ratios by fibrosis stage: F1, 1.58; F2, 2.52; F3, 3.48; F4, 6.44) and liver-related mortality grew exponentially with fibrosis progression (F1, 1.41, F2, 9.57; F3, 16.69; F4, 42.30) (18). In the largest paired biopsy study to date $(n=646$, mean follow-up 20 years) fibrosis stage alone independently predicted liver-related morbidity and overall mortality, whereas the presence of NASH had no significant bearing on outcomes (19).

Unsurprisingly given the cardiometabolic risk factors inherent to the metabolic syndrome, cardiovascular disease is the most common cause of death in NAFLD $(17,19,20)$. The intricate association with the metabolic syndrome complicates the distinction between NAFLD as an independent phenomenon in cardiometabolic disease pathogenesis and NAFLD as a bystander sharing common aetiological foundations with cardiometabolic disease (20). Epidemiological evidence links NAFLD to cerebrovascular, coronary and peripheral vascular disease, as well as to subclinical artery intima-media thickness and

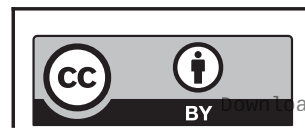

This work is licensed under a Creative Commons Attribution 4.0 International License. ded from Bioscientifica.com at 04/26/2023 10:02:46AM 
arterial wall stiffness (20). NAFLD is also closely associated with chronic kidney disease and early renal dysfunction with microalbuminuria (20). NAFLD and T2DM coexistence is common, promoting adverse outcomes in a synergistic and bi-directional manner. NAFLD is present in up to $70 \%$ of patients with T2DM, while NAFLD patients exhibit five-fold increased risks of T2DM development (21). T2DM and NAFLD coexistence is believed to drive micro- and macrovascular complications in T2DM and accelerate fibrogenesis in NAFLD (21). Insulin resistance is a cardinal feature of T2DM, cardiovascular disease and NAFLD pathogenesis, thereby potentially confounding the relationship between NAFLD and cardiometabolic outcomes (22).

Historically, NAFL was viewed as a benign disease state and NASH as its aggressive counterpart. Current evidence suggests that neither NAFL nor NASH, but only the presence of fibrosis directly influences clinically relevant outcomes. Do NAFL and NASH differ in their fibrogenic potential? In a systematic review of 221 patients with biopsy-proven NASH, $37.6 \%$ of patients demonstrated fibrosis progression over a 5.3 years mean follow-up (23). The indolent nature of NAFL was questioned by several small-scale longitudinal studies, observing fibrosis progression in $24-61 \%$ of NAFL patients with some individuals even reaching advanced fibrosis and end-stage liver disease $(24,25,26,27)$. In a meta-analysis of 411 NAFLD patients, $33.6 \%$ experienced fibrosis progression, $43.1 \%$ had static fibrosis stage, and $22.3 \%$ demonstrated fibrosis regression. This pooled analysis indicates that NAFLD is not always progressive, yet both NAFL and NASH appear to hold fibrogenic potential. If fibrosis progresses, however, it occurs approximately twice as quickly in NASH with an annual fibrosis progression rate of 0.14 stages compared to 0.07 stages in NAFL (28). Independent of NAFL/NASH status, $20 \%$ of patients with fibrosis progression were classified as 'rapid progressors' with the evolution from no fibrosis to advanced fibrosis in over just 6 years. Presently, no reliable methods exist to identify this high-risk subset of patients, although certain clinical features, especially obesity and T2DM, seem to confer increased risks of fibrosis progression, as detailed subsequently (28).

\section{Choosing your battles}

\section{Establishing the diagnosis}

In the absence of public screening programmes, NAFLD should be suspected in metabolically predisposed patients presenting with asymptomatically elevated aminotransferases or incidentally detected liver fat on abdominal imaging, prompting a comprehensive workup of all components of the metabolic syndrome and systematic exclusion of competing aetiologies of liver dysfunction (Table 1) (29). If symptoms are present, they are of non-specific nature, such as fatigue, mild right upper quadrant pain or epigastric fullness (8). NAFLD tends to remain asymptomatic until progression to end-stage liver disease and decompensation with ascites, hepatic encephalopathy and variceal haemorrhage occurs. While hepatomegaly and central adiposity are frequent, there are no pathognomonic examination findings in NAFLD. Rarer findings include acanthosis nigricans in insulin resistance and dorsocervical lipohypertrophy in NASH (8,

Table 1 Comprehensive assessment in suspected NAFLD.

\begin{tabular}{|c|c|c|c|}
\hline \multicolumn{4}{|c|}{ Comprehensive assessment in suspected NAFLD } \\
\hline \multicolumn{2}{|l|}{ Metabolic work-up } & \multicolumn{2}{|c|}{ Exclude secondary hepatic insults } \\
\hline $\begin{array}{l}\text { Type } 2 \text { diabetes } \\
\text { mellitus }\end{array}$ & $\begin{array}{l}\text { Fasting blood glucose, } \mathrm{HbA} 1 \mathrm{c} \text {, } \\
\text { oral glucose tolerance test }\end{array}$ & Alcohol excess & $>20$ g/day (women) and >30 g/day (men), AST:ALT ratio \\
\hline Obesity & $\begin{array}{l}\text { BMI, waist circumference, change } \\
\text { in weight }\end{array}$ & $\begin{array}{l}\text { Steatogenic } \\
\text { medication }\end{array}$ & $\begin{array}{l}\text { Amiodarone, diltiazem, steroids, valproic acid, } \\
\text { tamoxifen, anti-psychotics, highly active retroviral } \\
\text { therapy }\end{array}$ \\
\hline Hypertension & $\begin{array}{l}\text { Repeated blood pressure } \\
\text { monitoring }\end{array}$ & $\begin{array}{l}\text { Rare causes of } \\
\text { hepatic steatosis }\end{array}$ & $\begin{array}{l}\text { Refeeding syndrome, lipodystrophy, total parenteral } \\
\text { nutrition }\end{array}$ \\
\hline Dyslipidaemia & Serum total and HDL cholesterol & $\begin{array}{l}\text { Hepatitis B/C } \\
\text { infection }\end{array}$ & Viral hepatitis serology \\
\hline $\begin{array}{l}\text { Endocrine } \\
\text { disorders }\end{array}$ & $\begin{array}{l}\text { Hormonal profiling for } \\
\text { hypothyroidism, hypogonadism, } \\
\text { hypopituitarism and polycystic } \\
\text { ovarian syndrome }\end{array}$ & $\begin{array}{l}\text { Rare chronic liver } \\
\text { diseases }\end{array}$ & $\begin{array}{l}\text { Haemochromatosis (ferritin and transferrin saturation), } \\
\text { Wilsons disease (caeruloplasmin), autoimmune } \\
\text { hepatitis (immunoglobulins), alpha-1-antitrypsin } \\
\text { deficiency (alpha-1-antitrypsin levels) }\end{array}$ \\
\hline
\end{tabular}

ALT, alanine aminotransferase; AST, aspartate aminotransferase; HbA1c, haemoglobin A1c; HDL, high-density lipoprotein; NAFLD, non-alcoholic fatty liver disease.

https://ec.bioscientifica.com

https://doi.org/10.1530/EC-20-0174
(C) 2020 The authors Published by Bioscientifica Ltd

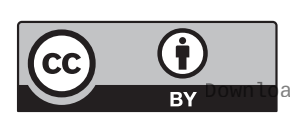

This work is licensed under a Creative Commons Attribution 4.0 International License. ded from Bioscientifica.com at $04 / 26 / 2023$ 10:02:46AM 
30). Since the prevalence of NAFLD in those with T2DM and obesity is substantial and most patients with NAFLD have normal liver biochemistry (1), there is an argument for suspecting NAFLD in all such patients and conducting risk stratification, although data to support such an approach is still being collated.

Initially, appropriate history taking should identify other causes of hepatic steatosis, including steatogenic medications (31), refeeding syndrome, total parenteral nutrition and lipodystrophy (32). Although excess alcohol intake requires exclusion as a common aetiology for liver steatosis, this is often difficult in clinical reality. In NAFLD, alanine aminotransferase (ALT) classically exceeds aspartate aminotransferase (AST) levels, while alcoholic liver disease frequently demonstrates AST:ALT ratios of $>1.5$ (32). With progressive fibrosis in NAFLD, however, AST levels may proportionally rise, increasing the AST:ALT ratio (32). NAFLD is the most common reason for raised transaminases (11), yet up to $78 \%$ of NAFLD patients exhibit non-elevated liver enzymes $(1,33)$, and even advanced disease often exists despite normal liver function tests (9). In fact, the entire histological continuum of NAFLD was observed in patients with normal liver biochemistry (34). This illustrates the imperfect nature of transaminases as prognostic and diagnostic tools in NAFLD, emphasising that clinicians should not rely upon transaminases to establish NAFLD diagnosis. Coexisting insults causing hepatic dysfunction should be ruled out through extended liver testing (Table 1) (35). Aberrations in serum levels of thyroid, sex and growth hormones are known to contribute to the development of metabolic syndrome and NAFLD, necessitating extended hormonal profiling if there is a high index of clinical suspicion for endocrine abnormalities (36).

Once NAFLD is suspected, evidence of hepatic steatosis is required to satisfy diagnostic criteria. Quantification of hepatic steatosis is prognostically insignificant, and steatosis often regresses as fibrosis progresses $(4,37)$. Abdominal ultrasound is the most accessible imaging modality for steatosis assessment and benefits from its non-invasiveness, low cost and absence of radiation. Ultrasound is sensitive (85\%) and specific (95\%) for detecting moderate to severe steatosis (>33\% steatotic hepatocytes); however, its sensitivity deteriorates when $<30 \%$ of hepatocytes are affected (38, 39). Increased echogenicity, the characteristic ultrasound finding in hepatic steatosis, is also present in fibrosis and early cirrhosis, reducing the reliability of ultrasound in coexisting liver disease aetiologies $(8,37,39)$. To overcome the limitations of traditional ultrasound in diagnosing mild steatosis, steatosis-specific imaging methods were developed. The controlled attenuation parameter (CAP) measures ultrasound attenuation by hepatic lipid content, demonstrating improved accuracy in detecting mild steatosis (steatosis $>10 \%$ AUROC 0.91) (37, 39, 40). Magnetic resonance-based imaging technologies measuring the proton density fat fraction (PDFF) are considered the gold standard for non-invasive steatosis assessment, enabling hepatic fat mapping with extremely high accuracy (AUROC 0.99). Magnetic resonance spectroscopy (MRS) assesses PDFF directly through differences in water and lipid peaks on resonance frequency domains, whereas MRI indirectly estimates water and fat content through time-dependent oscillations in MR signals (41). Due to its direct nature of measurement, potentially higher accuracy is ascribed to MRS, although MRI-PDFF demonstrated comparable operating performances across various studies (41). While MRI-PDFF permits steatosis quantification throughout the liver, MRS-PDFF evaluates single voxels of hepatic parenchyma, incurring risks of sampling bias. Both techniques are confined to research settings given the expense, infrastructure and expertise required for their acquisition and interpretation $(37,41)$.

Identifying those at greatest risk of disease progression or with already advanced disease is essential to efficiently target therapeutic interventions. As the current reference standard for diagnosis, prognosis and treatment response assessment in NAFLD, clinical trials rely heavily on liver biopsy, supplying investigators with a wealth of histological information about liver architecture, presence and extent of steatosis, necroinflammation and fibrosis (42). However, liver tissue acquired by biopsy represents merely $1 / 50,000$ of total liver volume and incurs significant risks of underestimating disease severity due to spatial sampling variability and non-uniform disease distribution $(37,39)$. Liver biopsies are expensive, invasive and prone to interobserver variability (37). The substantial epidemiological burden of NAFLD necessitates the implementation of more pragmatic approaches to diagnosis and risk stratification in clinical practice.

\section{Risk stratification}

Given that fibrosis is the strongest predictor of outcome, risk stratification based on fibrosis severity can determine who would benefit from liver-directed therapeutic interventions in specialist secondary care services. Certain populations of patients experience increased risks of NAFLD progression to advanced fibrosis. In comparison

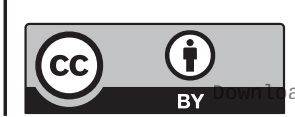

This work is licensed under a Creative Commons Attribution 4.0 International License. ded from Bioscientifica.com at 04/26/2023 10:02:46AM 
to pre-menopausal women, males and post-menopausal females displayed higher fibrosis stages with onset and duration of menopause as independent risk factors for fibrosis presence (43). The relationship between ethnicity and NAFLD severity is complex. While NAFLD prevalence is disproportionally lower among African American patients and higher among Hispanic patients compared to white populations, these discrepancies are less marked in high-risk cohorts (T2DM and obesity) and the rates of advanced fibrosis do not seem to differ significantly between ethnicities (44). This indicates that ethnicity may play a comparatively greater role in determining NAFLD prevalence rather than severity (45). Genetic susceptibility to NAFLD and its progression was first established by genome-wide association studies suggesting that ethnic disparities in NAFLD prevalence are, in part, dependent on patatin-like phospholipase domain-containing protein 3 (PNPLA3) genotypes $(46,47)$. Subsequent publications strengthened links between PNPLA3 polymorphisms, NAFLD susceptibility and advanced histology (47). Additional risk alleles such as TM6SF2 were since identified (48). Despite their common prevalence, these polymorphisms explain minor proportions of disease phenotype variability and are currently unsuitable for population-based risk assessment (47). In cross-sectional studies, age consistently predicted advanced fibrosis, yet this fails to persevere in longitudinal studies, implying that age reflects cumulative exposures to metabolic insults and disease duration rather than fibrosis progression rate $(28,43)$. Extensive evidence identified obese and diabetic patients as high-risk groups for fibrosis progression $(14,17,25,26,28,43)$. Accordingly, deterioration and improvement in fibrosis correlate with chronological weight gain or loss, respectively, while T2DM and NAFLD coexistence accelerates fibrogenesis $(21,43,49,50)$. Early histological data suggested that the risk of NASH could approach $40 \%$ in T2DM $(50,51)$. In a cross-sectional study of 1900 diabetic patients, the prevalence of advanced fibrosis was as high as $17.7 \%(50,52)$. In two recent histological studies investigating patients with concomitant T2DM and NAFLD, advanced fibrosis even reached $40-41 \%$ prevalence $(50,53,54)$.

There are many examples of non-invasive approaches to risk stratification in NAFLD including simple composite scoring systems, transient elastography or specialist panels for biomarkers of extracellular matrix remodelling. Simple scoring systems indirectly measure fibrogenesis and are derived from clinical risk factors of fibrosis progression (e.g. obesity, T2DM) and routinely available biochemistry reflecting liver dysfunction (AST, ALT, platelet count, albumin, etc). The NAFLD fibrosis score (NFS) and the Fibrosis-4 index (FIB-4) are two extensively validated, simple scoring systems with high negative predictive values for the exclusion of advanced fibrosis. The NFS (composed of BMI, age, presence of T2DM, AST:ALT ratio, platelet count and albumin) was specifically constructed and validated in biopsy-proven NAFLD $(34,37,55)$, whereas the FIB-4 algorithm (composed of AST, ALT, platelet count and age) was originally derived for use in hepatitis C/HIV coinfection and later effectively validated in NAFLD (35, 56). Both models utilise dual diagnostic cut-off values to exclude or diagnose advanced fibrosis. The NFS excludes advanced fibrosis with a negative predictive value (NPV) of $88-93 \%$ and detects advanced fibrosis with a positive predictive value (PPV) of $82-90 \%(35,55)$. The FIB-4 reliably excludes advanced fibrosis (NPV 90-95\%) and diagnoses advanced fibrosis with moderate accuracy (PPV $80 \%)(35,56)$. These simple models generally demonstrate inferior accuracy in discriminating between fibrosis stages compared to direct measures of fibrogenesis, yet their high negative likelihood ratios and accessibility make them valuable screening tools to exclude advanced fibrosis. While the NFS is more extensively validated, the FIB-4 performs slightly better in head-to-head comparisons and requires fewer variables for calculation, making it suitable for triaging NAFLD patients in primary care settings (8, $34,35)$. Both models generate indeterminate scores in a considerable proportion of cases (40-50\%) necessitating a two-tiered system for risk stratification (34). Depending on local accessibility and expertise, the second tier should involve transient elastography or proprietary panels which directly measures biomarkers of fibrogenesis/fibrinolysis.

One such commercial panel is the Enhanced Liver Fibrosis (ELFTM) Test which incorporates three fibrosis biomarkers: hyaluronic acid, tissue inhibitor of metalloproteinase-1 and amino-terminal propeptide of type III procollagen. ELF was validated in biopsy-proven NAFLD, exhibiting marginally improved accuracy in predicting advanced fibrosis for adult (AUROC 0.93) and paediatric (AUROC 0.99) patients compared to non-proprietary algorithms $(37,57,58)$. Its single diagnostic cut-off value for advanced fibrosis precludes indeterminate results; however, increased cost compared to non-commercial systems rationalise its position as a second-line risk stratification approach $(34,35)$.

Transient elastography (TE) technologies, such as FibroScan, are validated for hepatic fibrosis assessment in various liver disease aetiologies, including NAFLD (59). TE evaluates liver elasticity by measuring shear wave velocity, relying on the principle that hepatic parenchyma gradually 
loses elasticity with cumulative fibrotic tissue deposition. $\mathrm{TE}$ is a quick, painless and non-invasive procedure that assesses $1 / 500$ of total liver volume (1/50,000 for liver biopsy), ameliorating sampling bias (60). TE capably excludes advanced fibrosis with few false negatives and demonstrates superior accuracy in identifying advanced fibrosis (AUROC 0.93-0.95) compared to simple scores (35, 59). Pitfalls of TE include the lack of universally validated, diagnostic cut-off values for individual fibrosis stages and its considerable failure rate in clinical practice, especially with obese individuals (60). In a prospective study of $13,000 \mathrm{TE}$ examinations, failure rate ranged from $1 \%$ in lean patients to $42 \%$ in morbidly obese patients with an additional $16 \%$ unreliable readings, making nearly onefifth of all readings uninterpretable (61). Failure rates were reduced by the introduction of XL probes which cater towards obese patients $(35,37,60)$.

ELF or TE testing is recommended in the event of indeterminate outcomes from first-line non-commercial models (FIB-4, NFS) to classify those patients in the 'grey zone' (45). If test result discordance or diagnostic uncertainty persists after repeated non-invasive testing, consideration of liver biopsy is appropriate $(37,60)$. NAFLD patients categorised as low risk for significant hepatic fibrosis can be managed in primary care with therapeutic focus on cardiometabolic risk optimisation, since the probability of adverse liver-related outcomes within a 10 - to 15 -year time frame is low $(28,62)$. Highrisk patients warrant specialist hepatology referral for liver-focused management in addition to cardiometabolic risk factor control in secondary care settings (Fig. 1). Costeffectiveness analyses of this two-tiered risk stratification approach demonstrated five-fold increased detection rates of advanced fibrosis and cirrhosis while incurring specialist referral rates of $10 \%$ and reducing unnecessary referrals by $81 \%$ with significant cost savings $(34,42,63)$.

\section{Deploying your forces}

\section{The multidisciplinary approach}

The multisystemic nature of NAFLD necessitates a holistic management approach with a varying focus on hepatic and cardiometabolic risk control depending on the disease stage. A purely hepato-centric treatment approach would be unsatisfactory given that cardiovascular disease is the principal cause of mortality in NAFLD ( 40\%) with malignant and non-malignant liver diseases accounting for $10 \%$ of deaths (45). Integration of multidisciplinary pathways across primary and secondary care is required to achieve NAFLD diagnosis and risk assessment, therapeutic optimisation of cardiometabolic risk and diabetic control, adjustment of lifestyle and diet, as well as the initiation of liver-directed interventions and recruitment into clinical trials (45). The ideal multidisciplinary team would include expertise in hepatology, diabetology/endocrinology and/ or metabolic medicine, dietetics, lifestyle advice and weight management across primary and secondary care; however, resource limitations frequently hinder the completeness of multidisciplinary teams (64). Holistic, multidisciplinary management is widely advocated in NAFLD, yet few studies evaluated its real-world effectiveness and data favouring its utility remain scarce. Moolla et al. prospectively followed NAFLD patients attending a dedicated, multidisciplinary metabolic hepatology clinic in Oxford, UK, finding considerable improvements in liver and cardiometabolic health with reductions in ALT, weight, HbA1c, total cholesterol, QRisk3 score, and liver stiffness measurements (65).

\section{Optimisation of cardiometabolic risk}

Cardiometabolic interventions in NAFLD are founded on the central hypothesis that reversal of insulin resistance and hyperglycaemia alleviates cardiometabolic risk while simultaneously decelerating steatohepatitis activity and fibrosis (22). Independent of liver-related risk status and healthcare setting, lifestyle interventions targeting weight, diet and overall fitness remain the cornerstone of therapy for all NAFLD patients $(39,62$, 66). The incremental effect of weight loss on histological improvement is well documented; greater and more sustained weight loss correlating with more substantial histological improvements. Amelioration of ALT levels, steatosis and NASH is seen even with modest weight loss $(>5 \%)$, while NASH resolution and fibrosis regression were observed in higher degrees of weight reduction $(\geq 10 \%)$ $(62,64,67,68)$. A serial biopsy study $(n=293)$ found NASH resolution in $90 \%$ and fibrosis regression in $45 \%$ of patients who achieved $\geq 10 \%$ total body weight loss (68). However, the long-term effectiveness of lifestylebased weight loss interventions remains unclear, since these modifications are difficult to sustain. For example, only one in ten participants of the aforementioned study lost $\geq 10 \%$ total body weight and the vast majority (70\%) did not achieve even $\geq 5 \%$ weight loss. Carefully selected patients at low risk of hepatic decompensation and unresponsive to lifestyle interventions may benefit greatly from bariatric surgery, given its substantial impact

This work is licensed under a Creative Commons Attribution 4.0 International License. ded from Bioscientifica.com at 04/26/2023 10:02:46AM 


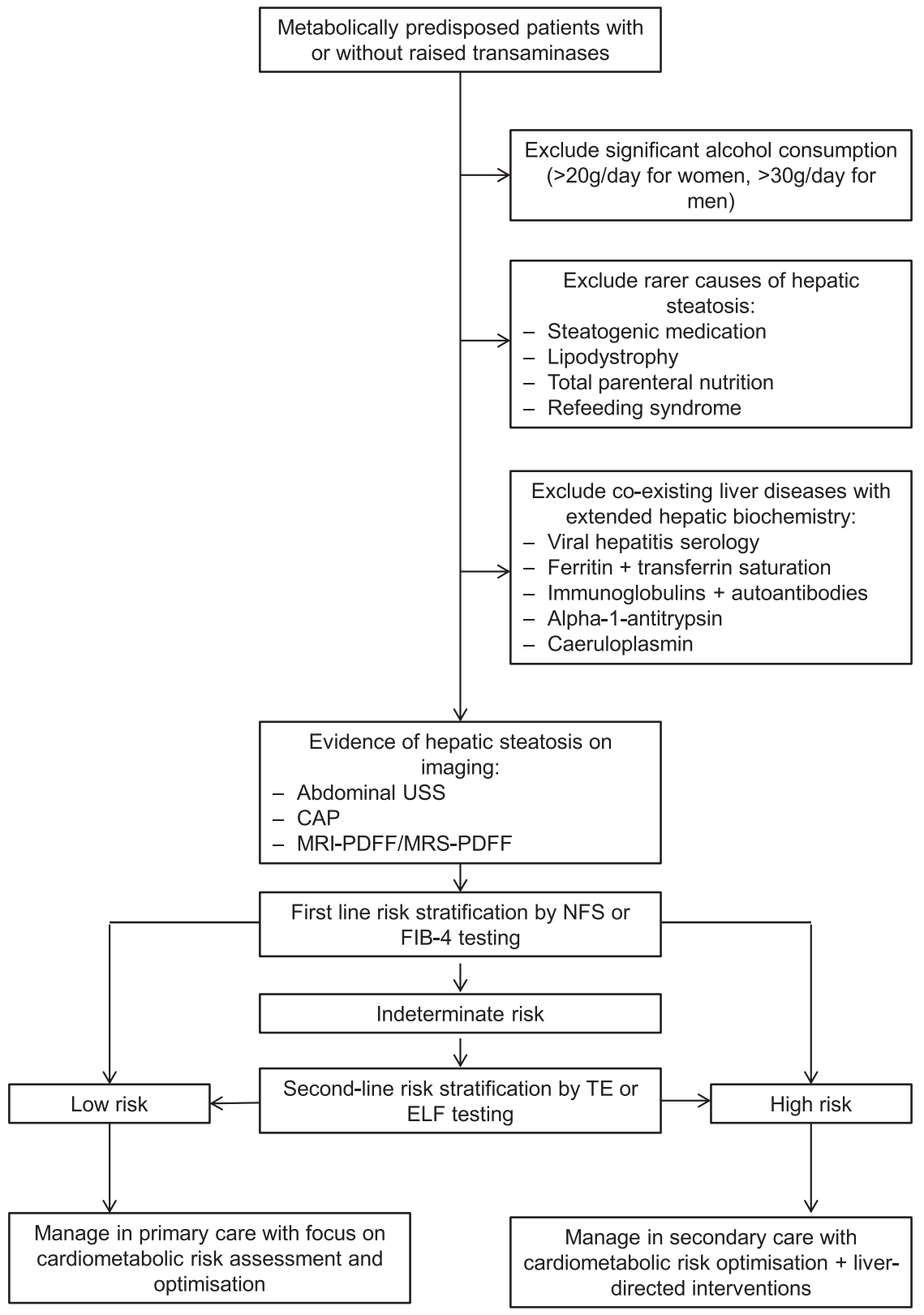

\section{Figure 1}

Suggested risk stratification algorithm in NAFLD. CAP, controlled attenuation parameter; ELF, enhanced liver fibrosis test; FIB-4, fibrosis-4 index; MRS, magnetic resonance spectroscopy; NFS, NAFLD fibrosis score; PDFF, protein density fat fraction; $T E$, transient elastography. on body weight and obesity-related comorbidities (45, 62). Roux-en-Y gastric bypass surgery remains the most effective treatment for obesity as it induces greater, more sustained weight loss than other procedures with almost immediate, weight-independent effects on glycaemic control, insulin sensitivity and GLP-1 secretion $(45,69)$. Sleeve gastrectomy produces less marked, but comparable, effects to Roux-en-Y bypass surgery without significantly altering upper gastrointestinal tract anatomy $(45,62,69)$. In a recent pooled analysis of 32 cohort studies, bariatric surgery resolved steatosis in $66 \%$, inflammation in $50 \%$, ballooning degeneration in $76 \%$ and fibrosis in $40 \%$ of patients (70). As NAFLD is not a primary indication for bariatric surgery and no randomised controlled trials exist in this field, these data cannot be regarded as level 1 evidence (62). Furthermore, 12\% of patients experienced worsening of NAFLD features following bariatric surgery (70). Mechanisms underpinning this deterioration are unknown, but were proposed to be related to the type of bariatric operation employed (45). No studies to date found reductions in liver-related mortality after bariatric surgery, underscoring the need for long-term, controlled trials in this area (69).

The role of dietary composition in NAFLD development and management is under extensive investigation. The ideal diet for NAFLD patients is yet
This work is licensed under a Creative Commons Attribution 4.0 International License. 
to be established. Diets high in polyunsaturated fatty acids (PUFA) exhibited beneficial effects upon insulin sensitivity, visceral adiposity, hepatic triglyceride content and steatohepatitis independent of weight reduction $(64,71)$. Two randomised trials compared isocaloric diets enriched in PUFAs and saturated fatty acids (SFA), finding that SFAs promote visceral and hepatic lipid storage, whereas PUFAs generated a three-fold increase in lean tissue $(72,73)$. Being rich in PUFAs, the potential liverspecific benefits of the Mediterranean diet were explored, after previously demonstrating protective effects on cardiovascular disease and diabetes risk - two highly relevant outcomes in NAFLD (64). In a 6-week crossover study, the Mediterranean diet improved hepatic steatosis and insulin sensitivity independent of weight loss compared to an isocaloric low-fat, high-carbohydrate diet (74). Calorie vs carbohydrate restriction was compared in one short-term dietary intervention study which favoured carbohydrate restriction for reducing hepatic steatosis despite similar weight loss profiles between groups (75). Isotope labelling studies highlighted the role of refined sugar intake (particularly fructose from industrial rather than fruit-derived sources) in hepatic lipotoxicity by facilitating de novo lipogenesis, depleting hepatic ATP and generating uric acid (6). Daily refined sugar intake was linked to lower steatosis grade but higher fibrosis stage (76). Fructose and refined sugar consumption should form part of thorough history taking in NAFLD and should be addressed accordingly (64).

Physical activity and exercise are strongly advocated for patients with NAFLD, although the evidence underpinning this management approach remains limited. Controlled studies with sufficient statistical power to outline exercise programmes or physical activity guidelines tailored to NAFLD patients are lacking (64). Mechanisms underlying proposed benefits of exercise in NAFLD pertain to improvements in peripheral insulin resistance, independent of weight loss (77). Pooled data from small-scale trials comparing aerobic and resistance exercise suggest that exercise in isolation (without weight loss) can generate relative reductions in hepatic lipid content by $20-30 \%$ (78). Variable forms of exercise (resistance, aerobic or high-intensity intermittent exercise) appear to have comparable impacts on hepatic steatosis $(64,78)$. Although emergent data indicate clinically meaningful benefits on steatosis reduction through exercise alone (20-30\%), this improvement is modest compared to weight loss which can generate $\geq 80 \%$ reductions in liver fat content $(64,79)$. Combined approaches integrating lifestyle-based interventions for weight management, diet and exercise with realistic, achievable goals and regular follow-up are advised.

\section{Diabetes control in NAFLD}

T2DM and NAFLD coexistence is a high-risk combination which synergistically accelerates morbidity, making optimisation of diabetic control imperative. The ideal anti-diabetic agent in NAFLD combines weight-reducing efficacy, cardiovascular event prevention, glycaemic control and cost-effectiveness while providing additional protective effects on liver histology (80).

The biguanide metformin is the first-line pharmacological agent for T2DM therapy and displays favourable effects on total body fat and insulin sensitivity. In a meta-analysis of 671 patients with NAFLD and T2DM, metformin failed to impact liver histology significantly despite reductions in HbA1c and weight (21, 81). Metformin does not appear to offer unique benefits in NAFLD and is not licensed for its treatment outside the context of diabetic control $(21,22)$.

Thiazolidinediones, selective ligands to peroxisomeproliferator-activated gamma receptors (PPAR gamma), act as insulin sensitisers by targeting adipocyte differentiation (50). In randomised, placebo-controlled trials (RCT), pioglitazone administration alleviated all histological characteristics of NASH (steatosis, inflammation, Mallory-Denk bodies and hepatocellular ballooning) in diabetic and non-diabetic patients $(82,83,84)$. Although significant effects on fibrosis were not evident in individual trials, a pooled analysis of RCTs indicated that pioglitazone therapy led to fibrosis regression (85). Outside its potential liver-centric benefits, pioglitazone decreased cardiovascular event incidence in patients with T2DM and outperformed other anti-diabetic medications with regards to mortality-rate reductions in a European cohort $(22,86)$. Concerns about extensive adverse effects (increased risk of fractures, fluid retention, bladder cancer and weight gain) currently preclude the wider use of pioglitazone in patients with T2DM and NAFLD, although the evidence supporting these adverse events is disputed $(21,62)$.

Dipeptidyl peptidase-4 (DPP-4) inhibitors increase incretin availability and are widely employed as adjunctive oral therapy in T2DM (21). DPP-4 inhibitors have neutral effects on cardiovascular outcomes in T2DM with no evidence for additional benefits of clinical relevance in NAFLD, although adequately powered, controlled studies with primary histological endpoints are lacking $(21,22)$.

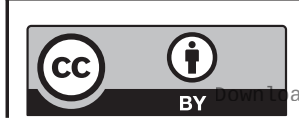

This work is licensed under a Creative Commons Attribution 4.0 International License. ded from Bioscientifica.com at 04/26/2023 10:02:46AM 
Incretin mimetics, particularly glucagon-like peptide-1 (GLP-1) receptor agonists, displayed attractive therapeutic potential in NAFLD and coexisting obesity and/or T2DM. GLP-1 agonists primarily stimulate glucose-dependent insulin secretion with important extra-pancreatic effects relating to satiety and insulin sensitivity $(21,50)$, thus improving glycaemic control and promoting weight loss via CNS modulation $(21,87)$. Meta-analysis of six phase III RCTs found that higher dose liraglutide $(1.8 \mathrm{mg})$ significantly decreased ALT and hepatic steatosis levels, an effect intimately related to the magnitude of weight reduction $(87,88)$. In the landmark proof-of-concept LEAN trial $(22,87)$, liraglutide administration led to NASH resolution in a higher proportion of patients (39\% vs $9 \%$ ) and to fibrosis progression in a lower proportion of patients ( $9 \%$ vs $36 \%$ ) compared with placebo (89). Whether weight loss exclusively lies at the heart of the mechanism underpinning phenotypic improvements needs to be clarified, although rodent studies suggest that these effects may be partly mediated by GLP-1 receptor expression $(21,90)$. In emerging data, semaglutide, a novel GLP-1 agonist, demonstrated superiority over older GLP-1 agonists in glycaemic control, weight reduction and cardiovascular event incidence $(91,92)$. The safety and efficacy of semaglutide in NAFLD is being investigated in phase II clinical trials.

Sodium-glucose transport protein-2 (SGLT-2) inhibitors impede renal glucose reabsorption, serving the dual purpose of lowering plasma glucose and enhancing caloric loss $(21,87)$. SGLT-2 therapy caused net weight reductions of $1.8 \mathrm{~kg}$ in a meta-analysis, probably as a consequence of caloric loss through glycosuria (93). SGLT-2 inhibitors are also associated with improved cardiovascular and all-cause mortality (94). In rodent models, SGLT-2 inhibition displayed protective effects on metabolic profiles and liver histology, including fibrosis (95). The translation of this benefit to human disease phenotypes is supported by sub-analyses of clinical trials showing significant reductions in transaminases with SGLT-2 therapy in T2DM (96). However, no controlled human studies of SGLT-2 inhibition in NAFLD with histological endpoints are available at present.

\section{Liver-specific and novel approaches}

The pharmacological landscape in NAFLD therapy is evolving rapidly, yet no licensed medications for NAFLD treatment currently exist. Several promising agents are undergoing phase III development. Liver-centred treatment approaches should complement, not replace, cardiometabolic risk profile management in NAFLD patients with progressive disease. Although an ideal intervention stage is not formally defined, patients with no or mild fibrosis and low risks of fibrosis progression present a small likelihood of advancing to meaningful, liver-related outcomes. Liver-specific therapy is unlikely to produce clinically relevant, cost-effective benefits for this patient cohort. Equally, patients with decompensated NASH cirrhosis may have progressed too far for antifibrotic pharmacotherapy to significantly alleviate liverrelated outcomes $(22,62)$, putting the focus of liver-specific therapies on patients with significant to advanced fibrosis (F2-F3) and compensated cirrhosis (F4). Selected patients at high risk of disease progression (e.g. NASH+T2DM with no fibrosis) may profit from liver-directed therapy following risk-benefit analysis (62).

Given the role of oxidative stress in hepatic fibrogenesis, two RCTs investigated the anti-oxidant properties of vitamin $\mathrm{E}$ in children and adults with NASH. In adults, vitamin E administration for 96 weeks reduced NAFLD activity score (NAS), but failed to achieve statistical significance for NASH resolution (82). In children, vitamin $\mathrm{E}$ therapy provided no overall benefit on liver biochemistry, steatosis or necroinflammation (97). In both trials, vitamin E therapy did not improve fibrosis significantly; however, neither trial was powered to detect clinically relevant anti-fibrotic effects (62). Longterm safety concerns regarding high-dose vitamin E use have surfaced and continue to be debated with some evidence indicating increased incidence of haemorrhagic stroke and prostate cancer $(45,98)$.

The dual and pan-peroxisome proliferator-activated receptor $(\operatorname{PPAR} \alpha / \delta)$ agonists elafibranor and lanifibranor are under active pursuit for the treatment of NASH as potent regulators of lipid metabolism (45). In animal models, elafibranor exhibited protective effects on hepatic lipid accumulation, necroinflammation and fibrosis progression (99). In the phase II GOLDEN-505 trial, elafibranor failed to achieve the primary endpoint of NASH resolution, but favoured histological improvements in more progressive disease (NAS $\geq 4$ ) on post hoc analysis (100). A multicentre, phase III trial is currently evaluating the efficacy of elafibranor in severe steatohepatitis (NAS $\geq 4$ ), although interim data outline that the trial did not meet its primary and secondary endpoints of NASH resolution and fibrosis improvement after a 72-week follow-up (https://clinicaltrials.gov/ct2/show/ NCT02704403; 101). Lanifibranor has universal, agonistic action on PPA receptors (pan-PPAR) and demonstrated fibro-protective properties in rodent models (102). 
A phase II trial of lanifibranor safety and efficacy in $\mathrm{NASH}$ is ongoing (https://clinicaltrials.gov/ct2/show/ NCT03008070).

Substantial evidence documents the importance of bile acids in nutritional homeostasis (62). Bile-acidinduced activation of the farnesoid $\mathrm{X}$ receptor (FXR) enhances insulin sensitivity and diminishes lipogenesis $(103,104)$. Obeticholic acid, a synthetic variant of the natural bile acid chenodeoxycholic acid, is a potent FXR ligand. The proof-of-concept, phase II FLINT trial of obeticholic acid therapy in NASH was terminated early after primary endpoints of efficacy were met during interim analysis, with 45 and $22 \%$ of patients in the intervention arm demonstrating histological improvement and NASH resolution (vs 21 and 13\% in the placebo arm), respectively (105). Although not powered to evaluate fibrosis resolution or progression, the FLINT trial observed protective effects on overall fibrogenesis, demonstrating fibrosis improvement in $35 \%$ of patients in the intervention arm (vs 19\% in the placebo arm) $(62,87,105)$. These encouraging outcomes initiated two ongoing, multicentre, phase III trials evaluating obeticholic acid effectiveness in NASH with fibrosis (REGENERATE) and compensated NASH cirrhosis (REVERSE) (https://clinicaltrials.gov/ ct2/show/NCT02548351; https://clinicaltrials.gov/ ct2/show/NCT03439254). In a promising interim analysis of the REGENERATE trial, $23 \%$ of patients in the intervention arm achieved the primary endpoint of fibrosis improvement (vs $12 \%$ in the placebo group, $P=0.0002)$ (106). Main adverse effects of obeticholic acid are pruritus ( $20 \%$ of patients), managed relatively successfully with topical emollients and anti-histamines in existing trials, and unfavourable serum cholesterol profiles (increased LDL, decreased HDL), generating fears of increased cardiovascular events (62). In rodent models, FXR agonism ameliorated atherosclerosis despite raising LDL levels (107). The impact of FXR agonism on cardiovascular event incidence in humans is unknown.

Other promising agents undergoing phase III development include selonsertib, which inhibits stressinduced regulators of inflammation and fibrosis, and cenicriviroc, which antagonises key drivers of monocyte recruitment and hepatic stellate cell activation (39, 45). In phase II trials, selonsertib and cenicriviroc demonstrated acceptable safety profiles and superiority over placebo in improving fibrosis $(108,109)$ with phase III trials in process (https://clinicaltrials.gov/ct2/show/ NCT03053050; https://clinicaltrials.gov/ct2/show/ NCT03028740)

\section{Conclusion}

NAFLD is a chronic liver disease that results in a high clinical burden due to the prevalence, inherent cardiometabolic risk and potential of progressing to cirrhosis. The presence and extent of fibrosis are the most important prognostic factors in NAFLD, necessitating risk stratification of patients by fibrosis stage with non-invasive methods. A multidisciplinary approach to treatment is advised, centred on minimisation of cardiometabolic risk as the cornerstone of therapy. Despite the current lack of licensed pharmacological agents for NAFLD management, several promising agents are undergoing advanced development to complement standard management in patients with progressive disease.

\section{Declaration of interest}

J F C has served on advisory boards and provided paid consultancy for Intercept, NovoNordisk and Alnylam. J W T has served on advisory boards and provided paid consultancy for Pfizer, AstraZeneca, Poxel, and NovoNordisk. D K has nothing to disclose.

\section{Funding}

The authors are supported by the National Institute for Health Research (NIHR) Oxford Biomedical Research Centre (BRC). The views expressed are those of the author(s) and not necessarily those of the NHS, the NIHR or the Department of Health.

\section{References}

1 Younossi ZM, Koenig AB, Abdelatif D, Fazel Y, Henry L \& Wymer M. Global epidemiology of nonalcoholic fatty liver disease - metaanalytic assessment of prevalence, incidence, and outcomes. Hepatology 201664 73-84. (https://doi.org/10.1002/hep.28431)

2 Neuschwander-Tetri BA. Non-alcoholic fatty liver disease. BMC Medicine 201715 45. (https://doi.org/10.1186/s12916-017-0806-8)

3 Younossi ZM, Blissett D, Blissett R, Henry L, Stepanova M, Younossi Y, Racila A, Hunt S \& Beckerman R. The economic and clinical burden of nonalcoholic fatty liver disease in the United States and Europe. Hepatology 201664 1577-1586. (https://doi.org/10.1002/hep.28785)

4 MacHado MV \& Diehl AM. Pathogenesis of nonalcoholic steatohepatitis. Gastroenterology 2016150 1769-1777. (https://doi. org/10.1053/j.gastro.2016.02.066)

5 Pierantonelli I \& Svegliati-Baroni G. Nonalcoholic fatty liver disease: basic pathogenetic mechanisms in the progression from NAFLD to NASH. Transplantation 2019103 e1-e13. (https://doi.org/10.1097/ TP.0000000000002480)

6 Friedman SL, Neuschwander-Tetri BA, Rinella M \& Sanyal AJ. Mechanisms of NAFLD development and therapeutic strategies. Nature Medicine 201824 908-922. (https://doi.org/10.1038/s41591018-0104-9)

7 Buzzetti E, Pinzani M \& Tsochatzis EA. The multiple-hit pathogenesis of non-alcoholic fatty liver disease (NAFLD). Metabolism: Clinical and Experimental 201665 1038-1048. (https://doi.org/10.1016/j. metabol.2015.12.012)

8 Rinella ME. Nonalcoholic fatty liver disease a systematic review. JAMA 2015313 2263-2273. (https://doi.org/10.1001/ jama.2015.5370)

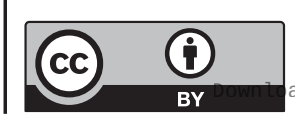

This work is licensed under a Creative Commons Attribution 4.0 International License. ded from Bioscientifica.com at 04/26/2023 10:02:46AM 
9 Fazel Y, Koenig AB, Sayiner M, Goodman ZD \& Younossi ZM. Epidemiology and natural history of non-alcoholic fatty liver disease. Metabolism: Clinical and Experimental 201665 1017-1025. (https:// doi.org/10.1016/j.metabol.2016.01.012)

10 Younossi ZM, Stepanova M, Afendy M, Fang Y, Younossi Y, Mir H \& Srishord M. Changes in the prevalence of the most common causes of chronic liver diseases in the United States from 1988 to 2008. YJCGH: Clinical Gastroenterology and Hepatology 20119 524.e1-530. e1. (https://doi.org/10.1016/j.cgh.2011.03.020)

11 Pais R, Barritt AS, Calmus Y, Scatton O, Runge T, Lebray P, Poynard T, Ratziu V \& Conti F. NAFLD and liver transplantation: current burden and expected challenges. Journal of Hepatology $2016 \mathbf{6 5} 1245-1257$ (https://doi.org/10.1016/j.jhep.2016.07.033)

12 Musso G, Gambino R, Cassader M \& Pagano G. Meta-analysis: natural history of non-alcoholic fatty liver disease (NAFLD) and diagnostic accuracy of non-invasive tests for liver disease severity. Annals of Medicine 201143 617-649. (https://doi.org/10.3109/07853 890.2010 .518623 )

13 Marengo A, Jouness RIK \& Bugianesi E. Progression and natural history of nonalcoholic fatty liver disease in adults. Clinics in Liver Disease 201620 313-324. (https://doi.org/10.1016/j.cld.2015.10.010)

14 Ekstedt M, Hagström H, Nasr P, Fredrikson M, Stål P, Kechagias S $\&$ Hultcrantz R. Fibrosis stage is the strongest predictor for diseasespecific mortality in NAFLD after up to 33 years of follow-up. Hepatology 201561 1547-1554. (https://doi.org/10.1002/hep.27368)

15 Brunt EM, Janney CG, di Bisceglie AM, Neuschwander-Tetri BA \& Bacon BR. Nonalcoholic steatohepatitis: a proposal for grading and staging the histological lesions. American Journal of Gastroenterology 199994 2467-2474. (https://doi.org/10.1111/j.15720241.1999.01377.x)

16 Stål P. Liver fibrosis in non-alcoholic fatty liver disease-diagnostic challenge with prognostic significance. World Journal of Gastroenterology 201521 11077-11087. (https://doi.org/10.3748/wjg.v21.i39.11077)

17 Angulo P, Kleiner DE, Dam-Larsen S, Adams LA, Bjornsson ES, Charatcharoenwitthaya P, Mills PR, Keach JC, Lafferty HD, Stahler A, et al. Liver fibrosis, but no other histologic features, is associated with long-term outcomes of patients with nonalcoholic fatty liver disease. Gastroenterology 2015149 389.e10-397.e10. (https://doi. org/10.1053/j.gastro.2015.04.043)

18 Dulai PS, Singh S, Patel J, Soni M, Prokop LJ, Younossi Z, Sebastiani G, Ekstedt M, Hagstrom H, Nasr P, et al. Increased risk of mortality by fibrosis stage in nonalcoholic fatty liver disease: systematic review and meta-analysis. Hepatology 201765 1557-1565. (https://doi.org/10.1002/hep.29085)

19 Hagström H, Nasr P, Ekstedt M, Hammar U, Stål P, Hultcrantz R \& Kechagias S. Fibrosis stage but not NASH predicts mortality and time to development of severe liver disease in biopsy-proven NAFLD. Journal of Hepatology 201767 1265-1273. (https://doi.org/10.1016/j. jhep.2017.07.027)

20 Adams LA, Anstee QM, Tilg H \& Targher G. Non-Alcoholic fatty liver disease and its relationship with cardiovascular disease and other extrahepatic diseases. Gut 201766 1138-1153. (https://doi org/10.1136/gutjnl-2017-313884)

21 Hazlehurst JM, Woods C, Marjot T, Cobbold JF \& Tomlinson JW. Non-alcoholic fatty liver disease and diabetes. Metabolism: Clinical and Experimental 201665 1096-1108. (https://doi.org/10.1016/j. metabol.2016.01.001)

22 Stefan N, Häring HU \& Cusi K. Non-alcoholic fatty liver disease: causes, diagnosis, cardiometabolic consequences, and treatment strategies. Lancet: Diabetes and Endocrinology 20197 313-324. (https://doi.org/10.1016/S2213-8587(18)30154-2)

23 Argo CK, Northup PG, Al-Osaimi AMS \& Caldwell SH. Systematic review of risk factors for fibrosis progression in non-alcoholic steatohepatitis. Journal of Hepatology 200951 371-379. (https://doi. org/10.1016/j.jhep.2009.03.0199)
24 McPherson S, Hardy T, Henderson E, Burt AD, Day CP \& Anstee QM. Evidence of NAFLD progression from steatosis to fibrosingsteatohepatitis using paired biopsies: implications for prognosis and clinical management. Journal of Hepatology 201562 1148-1155. (https://doi.org/10.1016/j.jhep.2014.11.034)

25 Pais R, Charlotte F, Fedchuk L, Bedossa P, Lebray P, Poynard T, Ratziu V \& LIDO Study Group. A systematic review of follow-up biopsies reveals disease progression in patients with non-alcoholic fatty liver. Journal of Hepatology 201359 550-556. (https://doi. org/10.1016/j.jhep.2013.04.027)

26 Wong VWS, Wong GLH, Choi PCL, Chan AWH, Li MKP, Chan HY, Chim AM, Yu J, Sung JJ \& Chan HL. Disease progression of nonalcoholic fatty liver disease: a prospective study with paired liver biopsies at 3 years. Gut 201059 969-974. (https://doi.org/10.1136/ gut.2009.205088)

27 Nasr P, Ignatova S, Kechagias S \& Ekstedt M. Natural history of nonalcoholic fatty liver disease: a prospective follow-up study with serial biopsies. Hepatology Communications 20182 199-210. (https:// doi.org/10.1002/hep4.1134)

28 Singh S, Allen AM, Wang Z, Prokop LJ, Murad MH \& Loomba R Fibrosis progression in nonalcoholic fatty liver vs nonalcoholic steatohepatitis: a systematic review and meta-analysis of pairedbiopsy studies. Clinical Gastroenterology and Hepatology 201513 643-654.e1. (https://doi.org/10.1016/j.cgh.2014.04.014)

29 European Association for the Study of the Liver (EASL), European Association for the Study of Diabetes (EASD) \& European Association for the Study of Obesity (EASO). EASL-EASD-EASO clinical practice guidelines for the management of non-alcoholic fatty liver disease. Journal of Hepatology $2016 \mathbf{6 4}$ 1388-1402. (https://doi.org/10.1016/j. jhep.2015.11.004)

30 Cheung O, Kapoor A, Puri P, Sistrun S, Luketic VA, Sargeant CC, Contos MJ, Shiffman ML, Stravitz RT, Sterling RK, et al. The impact of fat distribution on the severity of nonalcoholic fatty liver disease and metabolic syndrome. Hepatology 200746 1091-1100. (https:// doi.org/10.1002/hep.21803)

31 Bessone F, Dirchwolf M, Rodil MA, Razori MV \& Roma MG. Review article: drug-induced liver injury in the context of nonalcoholic fatty liver disease - a physiopathological and clinical integrated view. Alimentary Pharmacology and Therapeutics 201848 892-913. (https:// doi.org/10.1111/apt.14952)

32 Sattar N, Forrest E \& Preiss D. Non-alcoholic fatty liver disease. BMJ 2014349 g4596. (https://doi.org/10.1136/bmj.g4596)

33 Younossi ZM, Golabi P, de Avila L, Burns L, Afendy A, Fukui N, Qiu Y, Burns L, Afendy A, Nader F, et al. The global epidemiology of NAFLD and NASH in patients with type 2 diabetes: a systematic review and meta-analysis. Journal of Hepatology 201971 793-801. (https://doi. org/10.1016/j.jhep.2019.06.021)

34 Tsochatzis EA \& Newsome PN. NAFLD and the interface between primary and secondary care. Lancet: Gastroenterology and Hepatology 20183 509-517. (https://doi.org/10.1016/S2468-1253(18)30077-3)

35 Gallacher J \& McPherson S. Practical diagnosis and staging of nonalcoholic fatty liver disease: a narrative review 2018. Hepatology 20183 108-118.

36 Lonardo A, Mantovani A, Lugari S \& Targher G. NAFLD in some common endocrine diseases: prevalence, pathophysiology, and principles of diagnosis and management. International Journal of Molecular Sciences 201920 2841. (https://doi.org/10.3390/ ijms20112841)

37 Wai-Sun WV, Adams LA, de Lédinghen V, Lai-Hung Wong GL \& Sookoian S. Noninvasive biomarkers in NAFLD and NASH - current progress and future promise. Nature Reviews: Gastroenterology and Hepatology 201815 461-478. (https://doi.org/10.1038/s41575-0180014-9)

38 Hernaez R, Lazo M, Bonekamp S, Kamel I, Brancati FL, Guallar E \& Clark JM. Diagnostic accuracy and reliability of ultrasonography https://ec.bioscientifica.com https://doi.org/10.1530/EC-20-0174
(C) 2020 The authors Published by Bioscientifica Ltd

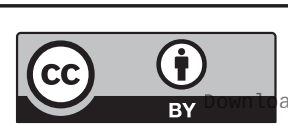

This work is licensed under a Creative Commons Attribution 4.0 International License. ded from Bioscientifica.com at 04/26/2023 10:02:46AM 
for the detection of fatty liver: a meta-analysis. Hepatology $20115 \mathbf{5 4}$ 1082-1090. (https://doi.org/10.1002/hep.24452)

39 Jennison E, Patel J, Scorletti E \& Byrne CD. Diagnosis and management of non-alcoholic fatty liver disease. Postgraduate Medical Journal 201995 314-322. (https://doi.org/10.1136/ postgradmedj-2018-136316)

40 Sasso M, Beaugrand M, de Ledinghen V, Douvin C, Marcellin P, Poupon R, Sandrin L \& Miette V. Controlled attenuation parameter (CAP): a novel VCTE ${ }^{\mathrm{TM}}$ guided ultrasonic attenuation measurement for the evaluation of hepatic steatosis: preliminary study and validation in a cohort of patients with chronic liver disease from various causes. Ultrasound in Medicine and Biology 201036 1825-1835. (https://doi.org/10.1016/j.ultrasmedbio.2010.07.005)

41 Dulai PS, Sirlin CB \& Loomba R. MRI and MRE for non-invasive quantitative assessment of hepatic steatosis and fibrosis in NAFLD and NASH: clinical trials to clinical practice. Journal of Hepatology 201665 1006-1016. (https://doi.org/10.1016/j.jhep.2016.06.005)

42 Crossan C, Tsochatzis EA, Longworth L, Gurusamy K, Davidson B, Rodríguez-Perálvarez M, Mantzoukis K, O’Brien J, Thalassinos E, Papastergiou V, et al. Cost-effectiveness of non-invasive methods for assessment and monitoring of liver fibrosis and cirrhosis in patients with chronic liver disease: systematic review and economic evaluation. Health Technology Assessment 201519 1-409.v. (https:// doi.org/10.3310/hta19090)

43 Bertot LC \& Adams LA. The natural course of non-alcoholic fatty liver disease. International Journal of Molecular Sciences 201617774. (https://doi.org/10.3390/ijms17050774)

44 Rich NE, Oji S, Mufti AR, Browning JD, Parikh ND, Odewole M, Mayo H \& Singal AG. Racial and ethnic disparities in nonalcoholic fatty liver disease prevalence, severity, and outcomes in the United States: a systematic review and meta-analysis. Clinical Gastroenterology and Hepatology 201816 198-210.e2. (https://doi.org/10.1016/j. cgh.2017.09.041)

45 Marjot T, Moolla A, Cobbold JF, Hodson L \& Tomlinson JW. Nonalcoholic fatty liver disease in adults: current concepts in etiology, outcomes and management. Endocrine Reviews 201941 bnz009. (https://doi.org/10.1210/endrev/bnz009)

46 Romeo S, Kozlitina J, Xing C, Pertsemlidis A, Cox D, Pennacchio LA, Boerwinkle E, Cohen JC \& Hobbs HH. Genetic variation in PNPLA3 confers susceptibility to nonalcoholic fatty liver disease. Nature Genetics 200840 1461-1465. (https://doi.org/10.1038/ng.257)

47 Loomba R \& Sanyal AJ. The global NAFLD epidemic. Nature Reviews: Gastroenterology and Hepatology 201310 686-690. (https://doi. org/10.1038/nrgastro.2013.171)

48 Liu YL, Reeves HL, Burt AD, Tiniakos D, Mcpherson S, Leathart JBS, Allison MED, Alexander GJ, Piguet AC, Anty R, et al. TM6SF2 rs58542926 influences hepatic fibrosis progression in patients with non-alcoholic fatty liver disease. Nature Communications 20145 4309. (https://doi.org/10.1038/ncomms5309)

49 Hossain N, Afendy A, Stepanova M, Nader F, Srishord M, Rafiq N, Goodman Z \& Younossi Z. Independent predictors of fibrosis in patients with nonalcoholic fatty liver disease. Clinical Gastroenterology and Hepatology 20097 1224-1229, 1229.e1. (https:// doi.org/10.1016/j.cgh.2009.06.007)

50 Tilg H, Moschen AR \& Roden M. Nafld and diabetes mellitus. Nature Reviews: Gastroenterology and Hepatology 2017 14 32-42. (https://doi. org/10.1038/nrgastro.2016.147)

51 Abrams GA, Kunde SS, Lazenby AJ \& Clements RH. Portal fibrosis and hepatic steatosis in morbidly obese subjects: a spectrum of nonalcoholic fatty liver disease. Hepatology $2004 \mathbf{4 0} 475-483$. (https://doi.org/10.1002/hep.20323)

52 Kwok R, Choi KC, Wong GLH, Zhang Y, Chan HLY, Luk AOY, Shu SST, Chan AWH, Yeung MW, Chan JCN, et al. Screening diabetic patients for non-alcoholic fatty liver disease with controlled attenuation parameter and liver stiffness measurements: a prospective cohort study. Gut 201665 1359-1368. (https://doi. org/10.1136/gutjnl-2015-309265)

53 Goh GBB, Pagadala MR, Dasarathy J, Unalp-Arida A, Sargent R, Hawkins C, Sourianarayanane A, Khiyami A, Yerian L, Pai RK, et al. Clinical spectrum of non-alcoholic fatty liver disease in diabetic and non-diabetic patients. BBA Clinical 20153 141-145. (https://doi. org/10.1016/j.bbacli.2014.09.001)

54 Bazick J, Donithan M, Neuschwander-Tetri BA, Kleiner D, Brunt EM, Wilson L, Doo E, Lavine J, Tonascia J \& Loomba R. Clinical model for NASH and advanced fibrosis in adult patients with diabetes and NAFLD: guidelines for referral in NAFLD. Diabetes Care 201538 1347-1355. (https://doi.org/10.2337/dc14-1239)

55 Angulo P, Hui JM, Marchesini G, Bugianesi E, George J, Farrell GC, Enders F, Saksena S, Burt AD, Bida JP, et al. The NAFLD fibrosis score: a noninvasive system that identifies liver fibrosis in patients with NAFLD. Hepatology 200745 846-854. (https://doi.org/10.1002/ hep.21496)

56 Sterling RK, Lissen E, Clumeck N, Sola R, Correa MC, Montaner J, Sulkowski MS, Torriani FJ, Dieterich DT, Thomas DL, et al. Development of a simple noninvasive index to predict significant fibrosis in patients with HIV/HCV coinfection. Hepatology 200643 1317-1325. (https://doi.org/10.1002/hep.21178)

57 Nobili V, Parkes J, Bottazzo G, Marcellini M, Cross R, Newman D, Vizzutti F, Pinzani M \& Rosenberg WM. Performance of ELF serum markers in predicting fibrosis stage in pediatric non-alcoholic fatty liver disease. Gastroenterology 2009136 160-167. (https://doi. org/10.1053/j.gastro.2008.09.013)

58 Guha IN, Parkes J, Roderick P, Chattopadhyay D, Cross R, Harris S, Kaye P, Burt AD, Ryder SD, Aithal GP, et al. Noninvasive markers of fibrosis in nonalcoholic fatty liver disease: validating the European liver fibrosis panel and exploring simple markers. Hepatology 200847 455-460. (https://doi.org/10.1002/hep.21984)

59 Wong VW-S, Vergniol J, Wong GL-H, Foucher J, Chan HL-Y, le Bail B, Choi PC-L, Kowo M, Chan AW-H, Merrouche W, et al. Diagnosis of fibrosis and cirrhosis using liver stiffness measurement in nonalcoholic fatty liver disease. Hepatology 201051 454-462. (https://doi.org/10.1002/hep.23312)

60 Kaswala DH, Lai M \& Afdhal NH. Fibrosis assessment in nonalcoholic fatty liver disease (NAFLD) in 2016. Digestive Diseases and Sciences 201661 1356-1364. (https://doi.org/10.1007/s10620-016-4079-4)

61 Castera L, Foucher J, Bernard PH, Carvalho F, Allaix D, Merrouche W, Couzigou P \& de Ledinghen V. Pitfalls of liver stiffness measurement: a 5-year prospective study of 13,369 examinations. Hepatology 2010 51 828-835. (https://doi.org/10.1002/hep.23425)

62 Rinella ME \& Sanyal AJ. Management of NAFLD: a stage-based approach. Nature Reviews: Gastroenterology and Hepatology 201613 196-205. (https://doi.org/10.1038/nrgastro.2016.3)

63 Srivastava A, Gailer R, Tanwar S, Trembling P, Parkes J, Rodger A Suri D, Thorburn D, Sennett K, Morgan S, et al. Prospective evaluation of a primary care referral pathway for patients with nonalcoholic fatty liver disease. Journal of Hepatology 201971 371-378. (doi:10.1016/j.jhep.2019.03.033)

64 Romero-Gómez M, Zelber-Sagi S \& Trenell M. Treatment of NAFLD with diet, physical activity and exercise. Journal of Hepatology 2017 67 829-846. (https://doi.org/10.1016/j.jhep.2017.05.016)

65 Moolla A, Motohashi K, Marjot T, Shard A, Ainsworth M, Gray A, Holman R, Pavlides M, Ryan JD, Tomlinson JW, et al. A multidisciplinary approach to the management of NAFLD is associated with improvement in markers of liver and cardiometabolic health. Frontline Gastroenterology 201910 337-346. (https://doi.org/10.1136/flgastro-2018-101155)

66 Spengler EK \& Loomba R. Recommendations for diagnosis, referral for liver biopsy, and treatment of nonalcoholic fatty liver disease and nonalcoholic steatohepatitis. Mayo Clinic Proceedings 201590 1233-1246. (https://doi.org/10.1016/j.mayocp.2015.06.013) https://ec.bioscientifica.com https://doi.org/10.1530/EC-20-0174 (c) 2020 The authors Published by Bioscientifica Ltd

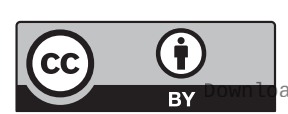

This work is licensed under a Creative Commons Attribution 4.0 International License. ded from Bioscientifica com at 04/26/2023 10:02:46AM 
67 Promrat K, Kleiner DE, Niemeier HM, Jackvony E, Kearns M, Wands JR, Fava JL \& Wing RR. Randomized controlled trial testing the effects of weight loss on nonalcoholic steatohepatitis. Hepatology 201051 121-129. (https://doi.org/10.1002/hep.23276)

68 Vilar-Gomez E, Martinez-Perez Y, Calzadilla-Bertot L, TorresGonzalez A, Gra-Oramas B, Gonzalez-Fabian L, Friedman SL, Diago M \& Romero-Gomez M. Weight loss through lifestyle modification significantly reduces features of nonalcoholic steatohepatitis. Gastroenterology 2015149 367-378.e5; quiz e14. (https://doi.org/10.1053/j.gastro.2015.04.005)

69 Laursen TL, Hagemann CA, Wei C, Kazankov K, Thomsen KL, Knop FK \& Grønbæk H. Bariatric surgery in patients with nonalcoholic fatty liver disease - from pathophysiology to clinical effects. World Journal of Hepatology 201911 138-149. (https://doi. org/10.4254/wjh.v11.i2.138)

70 Lee Y, Doumouras AG, Yu J, Brar K, Banfield L, Gmora S, Anvari M $\&$ Hong D. Complete resolution of nonalcoholic fatty liver disease after bariatric surgery: a systematic review and meta-analysis. Clinical Gastroenterology and Hepatology 201917 1040-1060.e11. (https://doi. org/10.1016/j.cgh.2018.10.017)

71 Sekiya M, Yahagi N, Matsuzaka T, Najima Y, Nakakuki M, Nagai R, Ishibashi S, Osuga JI, Yamada N \& Shimano H. Polyunsaturated fatty acids ameliorate hepatic steatosis in obese mice by SREBP-1 suppression. Hepatology 200338 1529-1539. (https://doi. org/10.1016/j.hep.2003.09.028)

72 Rosqvist F, Iggman D, Kullberg J, Cedernaes J, Johansson HE, Larsson A, Johansson L, Ahlström H, Arner P, Dahlman I, et al. Overfeeding polyunsaturated and saturated fat causes distinct effects on liver and visceral fat accumulation in humans. Diabetes 201463 2356-2368. (https://doi.org/10.2337/db13-1622)

73 Bjermo H, Iggman D, Kullberg J, Dahlman I, Johansson L, Persson L, Berglund J, Pulkki K, Basu S, Uusitupa M, et al. Effects of n-6 PUFAs compared with SFAs on liver fat, lipoproteins, and inflammation in abdominal obesity: a randomized controlled trial. American Journal of Clinical Nutrition 201295 1003-1012. (https://doi.org/10.3945/ ajcn.111.030114)

74 Ryan MC, Itsiopoulos C, Thodis T, Ward G, Trost N, Hofferberth S, O'Dea K, Desmond PV, Johnson NA \& Wilson AM. The Mediterranean diet improves hepatic steatosis and insulin sensitivity in individuals with non-alcoholic fatty liver disease. Journal of Hepatology 201359 138-143. (https://doi.org/10.1016/j. jhep.2013.02.012)

75 Browning JD, Baker JA, Rogers T, Davis J, Satapati S \& Burgess SC. Short-term weight loss and hepatic triglyceride reduction: evidence of a metabolic advantage with dietary carbohydrate restriction. American Journal of Clinical Nutrition 201193 1048-1052. (https:// doi.org/10.3945/ajcn.110.007674)

76 Abdelmalek MF, Suzuki A, Guy C, Unalp-Arida A, Colvin R, Johnson RJ, Diehl AM \& Nonalcoholic Steatohepatitis Clinical Research Network. Increased fructose consumption is associated with fibrosis severity in patients with nonalcoholic fatty liver disease. Hepatology 201051 1961-1971. (https://doi.org/10.1002/hep.23535)

77 Cuthbertson DJ, Shojaee-Moradie F, Sprung VS, Jones H, Pugh CJA Richardson P, Kemp GJ, Barrett M, Jackson NC, Louise Thomas EL, et al. Dissociation between exercise-induced reduction in liver fat and changes in hepatic and peripheral glucose homoeostasis in obese patients with non-alcoholic fatty liver disease. Clinical Science 2016 130 93-104. (https://doi.org/10.1042/CS20150447)

78 Hashida R, Kawaguchi T, Bekki M, Omoto M, Matsuse H, Nago T, Takano Y, Ueno T, Koga H, George J, et al. Aerobic vs. resistance exercise in non-alcoholic fatty liver disease: a systematic review. Journal of Hepatology 201766 142-152. (https://doi.org/10.1016/j. jhep.2016.08.023)

79 Thoma C, Day CP \& Trenell MI. Lifestyle interventions for the treatment of non-alcoholic fatty liver disease in adults: a systematic review. Journal of Hepatology 201256 255-266. (https://doi. org/10.1016/j.jhep.2011.06.010)

80 Sumida Y \& Yoneda M. Current and future pharmacological therapies for NAFLD/NASH. Journal of Gastroenterology 201853 362-376. (https://doi.org/10.1007/s00535-017-1415-1)

81 Musso G, Cassader M, Rosina F \& Gambino R. Impact of current treatments on liver disease, glucose metabolism and cardiovascular risk in non-alcoholic fatty liver disease (NAFLD): a systematic review and meta-analysis of randomised trials. Diabetologia 201255 885-904. (https://doi.org/10.1007/s00125-011-2446-4)

82 Sanyal AJ, Chalasani N, Kowdley KV, McCullough A, Diehl AM, Bass NM, Neuschwander-Tetri BA, Lavine JE, Tonascia J, Unalp A, et al. Pioglitazone, vitamin E, or placebo for nonalcoholic steatohepatitis. New England Journal of Medicine 2010362 1675-1685. (https://doi.org/10.1056/NEJMoa0907929)

83 Aithal GP, Thomas JA, Kaye PV, Lawson A, Ryder SD, Spendlove I, Austin AS, Freeman JG, Morgan L \& Webber J. Randomized, placebo-controlled trial of pioglitazone in nondiabetic subjects with nonalcoholic steatohepatitis. Gastroenterology 2008135 1176-1184. (https://doi.org/10.1053/j.gastro.2008.06.047)

84 Belfort R, Harrison SA, Brown K, Darland C, Finch J, Hardies J, Balas B, Gastaldelli A, Tio F, Pulcini J, et al. A placebo-controlled trial of pioglitazone in subjects with nonalcoholic steatohepatitis. New England Journal of Medicine 2006355 2297-2307. (https://doi. org/10.1056/NEJMoa060326)

85 Mahady SE, Webster AC, Walker S, Sanyal A \& George J. The role of thiazolidinediones in non-alcoholic steatohepatitis - a systematic review and meta analysis. Journal of Hepatology 201155 1383-1390. (https://doi.org/10.1016/j.jhep.2011.03.016)

86 Strongman H, Christopher S, Majak M, Williams R, Bahmanyar S, Linder M, Heintjes EM, Bennett D, Korhonen P \& Hoti F.

Pioglitazone and cause-specific risk of mortality in patients with type 2 diabetes: extended analysis from a European multidatabase cohort study. BMJ Open Diabetes Research and Care 20186 e000481. (https:// doi.org/10.1136/bmjdrc-2017-000481)

87 Barb D, Portillo-Sanchez P \& Cusi K. Pharmacological management of nonalcoholic fatty liver disease. Metabolism: Clinical and Experimental 201665 1183-1195. (https://doi.org/10.1016/j.metabol.2016.04.004)

88 Armstrong MJ, Houlihan DD, Rowe IA, Clausen WHO, Elbrønd B, Gough SCL, Tomlinson JW \& Newsome PN. Safety and efficacy of liraglutide in patients with type 2 diabetes and elevated liver enzymes: Individual patient data meta-analysis of the LEAD program. Alimentary Pharmacology and Therapeutics 201337 234-242. (https://doi.org/10.1111/apt.12149)

89 Armstrong MJ, Gaunt P, Aithal GP, Barton D, Hull D, Parker R, Hazlehurst JM, Guo K, LEAN Trial Team, Abouda G, et al. Liraglutide safety and efficacy in patients with non-alcoholic steatohepatitis (LEAN): a multicentre, double-blind, randomised, placebo-controlled phase 2 study. Lancet 2016387 679-690. (https://doi.org/10.1016/ S0140-6736(15)00803-X)

90 Trevaskis JL, Griffin PS, Wittmer C, Neuschwander-Tetri BA, Brunt EM, Dolman CS, Erickson MR, Napora J, Parkes DG \& Roth JD. Glucagon-like peptide-1 receptor agonism improves metabolic, biochemical, and histopathological indices of nonalcoholic steatohepatitis in mice. American Journal of Physiology: Gastrointestinal and Liver Physiology 2012302 G762-G772. (https://doi.org/10.1152/ ajpgi.00476.2011)

91 Pratley RE, Aroda VR, Lingvay I, Lüdemann J, Andreassen C, Navarria A, Viljoen A \& SUSTAIN 7 Investigators. Semaglutide versus dulaglutide once weekly in patients with type 2 diabetes (SUSTAIN 7): a randomised, open-label, phase $3 \mathrm{~b}$ trial. Lancet: Diabetes and Endocrinology 20186 275-286. (https://doi.org/10.1016/S22138587(18)30024-X)

92 Marso SP, Bain SC, Consoli A, Eliaschewitz FG, Jódar E, Leiter LA, Lingvay I, Rosenstock J, Seufert J, Warren ML, et al. Semaglutide https://ec.bioscientifica.com https://doi.org/10.1530/EC-20-0174 (c) 2020 The authors Published by Bioscientifica Ltd

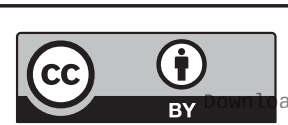

This work is licensed under a Creative Commons Attribution 4.0 International License. ded from Bioscientifica com at 04/26/2023 10:02:46AM 
and cardiovascular outcomes in patients with type 2 diabetes. New England Journal of Medicine 2016375 1834-1844. (https://doi. org/10.1056/NEJMoa1607141)

93 Vasilakou D, Karagiannis T, Athanasiadou E, Mainou M, Liakos A, Bekiari E, Sarigianni M, Matthews DR \& Tsapas A. Sodium-glucose cotransporter 2 inhibitors for type 2 diabetes: a systematic review and meta-analysis. Annals of Internal Medicine 2013159 262-274. (https://doi.org/10.7326/0003-4819-159-4-201308200-00007)

94 Zinman B, Wanner C, Lachin JM, Fitchett D, Bluhmki E, Hantel S, Mattheus M, Devins T, Johansen OE, Woerle HJ, et al. Empagliflozin, cardiovascular outcomes, and mortality in type 2 diabetes. New England Journal of Medicine 2015373 2117-2128. (https://doi. org/10.1056/NEJMoa1504720)

95 Hayashizaki-Someya Y, Kurosaki E, Takasu T, Mitori H, Yamazaki S, Koide K \& Takakura S. Ipragliflozin, an SGLT2 inhibitor, exhibits a prophylactic effect on hepatic steatosis and fibrosis induced by choline-deficient l-amino acid-defined diet in rats. European Journal of Pharmacology 2015754 19-24. (https://doi.org/10.1016/j. ejphar.2015.02.009)

96 Leiter LA, Forst T, Polidori D, Balis DA, Xie J \& Sha S. Effect of canagliflozin on liver function tests in patients with type 2 diabetes. Diabetes and Metabolism 201642 25-32. (https://doi.org/10.1016/j. diabet.2015.10.003)

97 Lavine JE, Schwimmer JB, van Natta ML, Molleston JP, Murray KF, Rosenthal P, Abrams SH, Scheimann AO, Sanyal AJ, Chalasani N, et al. Effect of vitamin $\mathrm{E}$ or metformin for treatment of nonalcoholic fatty liver disease in children and adolescents the tonic randomized controlled trial. JAMA 2011305 1659-1668. (https://doi org/10.1001/jama.2011.520)

98 Miller ER, Pastor-Barriuso R, Dalal D, Riemersma RA, Appel LJ \& Guallar E. Meta-analysis: high-dosage vitamin E supplementation may increase all-cause mortality. Annals of Internal Medicine 2005142 37-46. (https://doi.org/10.7326/0003-4819-142-1-200501040-00110)

99 Staels B, Rubenstrunk A, Noel B, Rigou G, Delataille P, Millatt LJ, Baron M, Lucas A, Tailleux A, Hum DW, et al. Hepatoprotective effects of the dual peroxisome proliferator-activated receptor alpha/ delta agonist, GFT505, in rodent models of nonalcoholic fatty liver disease/nonalcoholic steatohepatitis. Hepatology 201358 1941-1952. (https://doi.org/10.1002/hep.26461)

100 Ratziu V, Harrison SA, Francque S, Bedossa P, Lehert P, Serfaty L, Romero-Gomez M, Boursier J, Abdelmalek M, Caldwell S, et al. Elafibranor, an agonist of the peroxisome proliferator-activated receptor- $\alpha$ and $-\delta$, induces resolution of nonalcoholic steatohepatitis without fibrosis worsening. Gastroenterology 2016150 1147-1159.e5 (https://doi.org/10.1053/j.gastro.2016.01.038)

101 GENFIT. GENFIT: announces results from interim analysis of RESOLVE-IT phase 3 trial of elafibranor in adults with NASH and
Fibrosis. [press release]. Loos, France: Genfit, 2020. (available at: https://ir.genfit.com/news-releases/news-release-details/genfitannounces-results-interim-analysis-resolve-it-phase-3)

102 Wettstein G, Luccarini JM, Poekes L, Faye P, Kupkowski F, Adarbes V, Defrêne E, Estivalet C, Gawronski X, Jantzen I, et al. The new-generation pan-peroxisome proliferator-activated receptor agonist IVA337 protects the liver from metabolic disorders and fibrosis. Hepatology Communications 20171 524-537. (https://doi. org/10.1002/hep4.1057)

103 Mudaliar S, Henry RR, Sanyal AJ, Morrow L, Marschall HU, Kipnes M, Adorini L, Sciacca CI, Clopton P, Castelloe E, et al. Efficacy and safety of the farnesoid $\mathrm{X}$ receptor agonist obeticholic acid in patients with type 2 diabetes and nonalcoholic fatty liver disease. Gastroenterology 2013145 574.e1-582.e1. (https://doi.org/10.1053/j. gastro.2013.05.042)

104 Fang S, Suh JM, Reilly SM, Yu E, Osborn O, Lackey D, Yoshihara E, Perino A, Jacinto S, Lukasheva Y, et al. Intestinal FXR agonism promotes adipose tissue browning and reduces obesity and insulin resistance. Nature Medicine 201521 159-165. (https://doi. org/10.1038/nm.3760)

105 Neuschwander-Tetri BA, Loomba R, Sanyal AJ, Lavine JE, van Natta ML, Abdelmalek MF, Chalasani N, Dasarathy S, Diehl AM, Hameed B, et al. Farnesoid X nuclear receptor ligand obeticholic acid for non-cirrhotic, non-alcoholic steatohepatitis (flint): a multicentre, randomised, placebo-controlled trial. Lancet 2015385 956-965. (https://doi.org/10.1016/S0140-6736(14)61933-4)

106 Younossi ZM, Ratziu V, Loomba R, Rinella M, Anstee QM, Goodman Z, Bedossa P, Geier A, Beckebaum S, Newsome PN, et al. Obeticholic acid for the treatment of non-alcoholic steatohepatitis: interim analysis from a multicentre, randomised, placebo-controlled phase 3 trial. Lancet 2019394 2184-2196. (https://doi.org/10.1016/ S0140-6736(19)33041-7)

107 Miyazaki-Anzai S, Masuda M, Levi M, Keenan AL \& Miyazaki M. Dual activation of the bile acid nuclear receptor FXR and G-proteincoupled receptor TGR5 protects mice against atherosclerosis. PLoS ONE 20149 e108270. (https://doi.org/10.1371/journal. pone.0108270)

108 Friedman SL, Ratziu V, Harrison SA, Abdelmalek MF, Aithal GP, Caballeria J, Francque S, Farrell G, Kowdley KV, Craxi A, et al. A randomized, placebo-controlled trial of cenicriviroc for treatment of nonalcoholic steatohepatitis with fibrosis. Hepatology $2018 \mathbf{6 7}$ 1754-1767. (https://doi.org/10.1002/hep.29477)

109 Loomba R, Lawitz E, Mantry PS, Jayakumar S, Caldwell SH, Arnold H, Diehl AM, Djedjos CS, Han L, Myers RP, et al. The ASK1 inhibitor selonsertib in patients with nonalcoholic steatohepatitis: a randomized, phase 2 trial. Hepatology 201867 549-559. (https://doi. org/10.1002/hep.29514)

Received in final form 21 June 2020

Accepted 2 July 2020

Accepted Manuscript published online 3 June 2020 https://ec.bioscientifica.com

https://doi.org/10.1530/EC-20-0174
(C) 2020 The authors Published by Bioscientifica Ltd

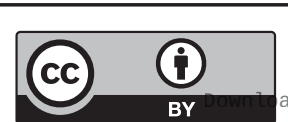

This work is licensed under a Creative Commons Attribution 4.0 International License. ded from Bioscientifica com at 04/26/2023 10:02:46AM 